\title{
Obstáculos y fortalezas del régimen legal que protege los bienes de interés cultural del ámbito nacional*
}

\author{
Anny Yahaira Riveros Rojas** \\ Recibido: 6 de junio de 2018 - Aprobado: 15 de agosto de 2018
}

\section{Resumen}

Por medio de este escrito se pretende dar a conocer el régimen legal que cobija a los bienes de interés cultural del ámbito nacional, partiendo de un análisis minucioso y descriptivo que permita al lector conocer detalladamente sobre el marco legal, su aplicabilidad, las sanciones procedentes para el que infrinja dicho régimen, junto con los sujetos sobre los cuales puede recaer la infracción; cumpliendo así con los objetivos del presente artículo, los cuales versan en conocer su normatividad, analizar las fortalezas del régimen legal, diagnosticar los posibles obstáculos que se presentan en la vida práctica cuando se aplica el citado régimen y establecer propuestas de mejora al régimen legal para propender por los valores históricos de los bienes de interés cultural del ámbito nacional junto con su salvaguardia y protección. A su vez, se da respuesta al problema jurídico planteado el cual es determinar las fortalezas y obstáculos del régimen legal que protege a los bienes de interés cultural del ámbito nacional, explicando así la naturaleza y alcance de los procedimientos administrativos sancionatorios que los cobijan, los cuales se adelantan producto de las infracciones al citado régimen. La metodología utilizada fue la cualitativa,

\footnotetext{
*El presente artículo es producto de la investigación: “Obstáculos y fortalezas del régimen legal que protege los bienes de interés cultural del ámbito nacional”, gestionado en el marco de la especialización en Derecho Administrativo, Universidad Libre, Bogotá D. C., Colombia. Citar como: Riveros Rojas, A.Y.(2019). Obstáculos y fortalezas del régimen legal que protege los bienes de interés cultural del ámbito nacional. Revista IUSTA,1(50), 145-176. DOI: https://doi.org/10.15332/1900-0448.2019.0050.06

** Abogada de la Universidad Libre, Bogotá, D. C., Colombia. Especialista en Derecho Administrativo, Universidad Libre, Bogotá D. C., Colombia. Correo electrónico: annyriveros11@ hotmail.com
} 
ya que la investigación del artículo se basó en un análisis subjetivo producto de la recolección de datos, vivencias prácticas y a casos que han sido tramitados por el Ministerio de Cultura, sobre los cuales se logró establecer un método descriptivo, logrando así evidenciar las fortalezas y obstáculos del régimen legal siendo posible plantear propuestas para que la ciudadanía tenga más sentido de pertenencia y ayude así a salvaguardar y proteger los bienes de interés cultural.

Palabras clave: patrimonio, nación, cultura, sanción, bienes de interés cultural.

\title{
OBSTACLES AND STRENGTHS OF THE LEGAL REGIME THAT PROTECTS CULTURAL ASSETS OF NATIONAL SCOPE
}

\begin{abstract}
Through this writing, it is intended to publicize the legal regime that covers cultural assets of national scope, starting from a thorough and descriptive analysis that allows the reader to know in detail about the legal framework, its applicability, the sanctions coming for the one who infringes said regime, together with the subjects on which the infraction can fall; complying with the objectives of this article, which are to know their regulations, analyze the strengths of the legal regime, diagnose possible obstacles that arise in the practical life when applying the aforementioned regime and establish proposals for improvement to the legal regime to propender for the historical values of the Assets of Cultural Interest of the National scope and its safeguard and protection. In turn, it responds to the legal problem posed which is to determine the strengths and obstacles of the legal regime that protects cultural assets of national scope, thus explaining the nature and scope of the Administrative Sanctions Procedures that shelter them, the which are anticipated as a result of the infractions to the aforementioned regime. The methodology used was qualitative, since the research of the article was based on a subjective analysis product of data collection, practical experiences and cases that have been processed by the Ministry of Culture, on which a descriptive method was established, thus achieving evidence of the strengths and obstacles of the legal regime being possible to propose proposals for citizens to have more sense of belonging, and help safeguard and protect cultural assets.
\end{abstract}

Keywords: patrimony, nation, culture, sanction, goods of cultural interest. 


\section{OBSTÁCULOS E PONTOS FORTES DO REGIME JURÍDICO QUE PROTEGE OS BENS CULTURAIS DE ÂMBITO NACIONAL}

\section{Resumo}

Por meio deste documento, pretende-se dar a conhecer o regime jurídico que abrange os bens de interesse cultural do âmbito nacional, a partir de uma análise minuciosa e descritiva que permite ao leitor conhecer em detalhe o enquadramento legal, a sua aplicabilidade, as sanções impostas a quem infringe o referido regime, juntamente com os assuntos sobre os quais a infracção pode cair; cumprindo os objetivos deste artigo, que são conhecer suas regulamentações, analisar os pontos fortes do regime jurídico, diagnosticar possíveis entraves que surgem na vida prática quando o referido regime é aplicado e estabelecer propostas de melhoria do regime jurídico para promover os valores históricos dos Ativos de Interesse Cultural do Âmbito Nacional em conjunto com sua salvaguarda e proteção. Por sua vez, a resposta é dada para o problema legal levantada que é determinar os pontos fortes e os obstáculos do regime jurídico que protege os bens culturais a nível nacional, o que explica a natureza e extensão dos processos administrativos punitivos que abrigam, o que são antecipados como resultado das infrações ao regime acima mencionado. A metodologia utilizada foi qualitativa, uma vez que a pesquisa do artigo baseou-se em um produto de análise subjetiva de coleta de dados, experiências práticas e casos que foram processados pelo Ministério da Cultura, sobre o qual foi estabelecido um método descritivo, obtendo assim provas dos pontos fortes e obstáculos do regime jurídico, sendo possível propor propostas para que os cidadãos tenham mais sentido de pertença e, assim, ajudar a salvaguardar e proteger os bens de interesse cultural.

Palavras-chave: patrimônio, nação, cultura, sanção, bens de interesse cultural. 


\section{Introducción}

Siempre que se hace referencia a los sujetos de derechos normalmente se asimilan estos con el concepto de persona, entendiendo a este criterio como la única concepción que existe dentro de la categoría de sujetos de derechos sin que se incluyan otras concepciones tales como la de sujeto de relevancia jurídica, que sin duda también son sujetos de especial protección, etc. (Herrera, 2018).

A lo largo de la historia de nuestro país, se ha establecido que el patrimonio cultural de la nación es el conjunto de bienes y valores culturales que son expresión de la nacionalidad colombiana, como la tradición, las costumbres y los hábitos, así como los bienes inmateriales y materiales, muebles e inmuebles. Así pues, en las líneas de este artículo se realizará un análisis del régimen legal que cobija a los bienes inmuebles que han sido declarados como bienes de interés cultural (Llano, 2017).

Muchas de las personas que viven en el territorio nacional no saben a qué tipo de sanciones están sometidas aquellas personas que realizan intervenciones tales como construcciones, demoliciones u obras de reparación en bienes de interés cultural, o inmuebles que están dentro del área afectada o su zona de influencia, sin autorización previa del Ministerio de Cultura, sino que las conocen cuando se les comunica la existencia de méritos para adelantar un procedimiento administrativo sancionatorio y formulación de pliego de cargos por las intervenciones realizadas.

Es por ello que uno de los objetos de este artículo es poder dejar claro a la ciudadanía que las licencias de construcción otorgadas por los curadores urbanos o por las Secretarías de Planeación no son suficientes para poder realizar intervenciones en inmuebles con características de bien de interés cultural del ámbito nacional que estén dentro del área afectada o su zona de influencia, debido a que uno es el proceso urbanístico el cual se adelanta ante los citados entes y otros son los tramites que se deben adelantar ante el Ministerio de Cultura para la obtención de los permisos correspondientes para poder intervenirlos, donde como consecuencia de su omisión, pueden llegar a ser penalizados con una sanción pecuniaria que oscila entre 200 y 500 SMLMV (salarios mínimos legales mensuales vigentes).

Ahora bien, se considera de gran importancia dar a conocer el contenido de este artículo junto con la regulación normativa y descripción de las fortalezas y obstáculos del régimen legal, debido a que en casos fallados por el Ministerio de Cultura, se observa que las personas que adquieren inmuebles que están dentro del área afectada o zona de influencia de un BIC, desconocen tal calidad y por ende 
las intervenciones que pueden realizar; es por ello que se plantean una serie de alternativas que ayuden a acrecentar un sentido de pertenencia y responsabilidad por el patrimonio cultural.

\section{Régimen legal de los bienes de interés cultural del ámbito nacional}

Para poder hablar de los bienes de interés cultural del ámbito nacional es preciso aclarar que estos se encuentran cobijados dentro de la definición de patrimonio cultural de la nación ${ }^{1}$, la cual establece:

El patrimonio cultural de la nación está constituido por todos los bienes y valores culturales que son expresión de la nacionalidad colombiana, tales como la tradición, las costumbres y los hábitos, así como el conjunto de bienes inmateriales y $\underline{\text { materiales }}^{2}$, muebles e inmuebles, que poseen un especial interés histórico, artístico, estético, plástico, arquitectónico, urbano, arqueológico, ambiental, ecológico, lingüístico, sonoro, musical, audiovisual, fílmico, científico, testimonial, documental, literario, bibliográfico, museológico, antropológico y las manifestaciones, los productos y las representaciones de la cultura popular (Ley 397, 1997, art. 4) (subrayado por fuera del texto original).

En virtud de lo expuesto, la Constitución Política de Colombia en su artículo 72 ha establecido:

Artículo 72. El patrimonio cultural de la nación está bajo la protección del Estado. E1 patrimonio arqueológico y otros bienes culturales que conforman la identidad nacional, pertenecen a la nación y son inalienables, inembargables e

1 El Ministerio de Cultura concibe el patrimonio cultural de manera incluyente, diversa y participativa, como una suma de bienes y manifestaciones que abarca un vasto campo de la vida social y está constituida por un complejo conjunto de activos sociales de carácter cultural (material e inmaterial), que le dan a un grupo humano sentido, identidad y pertenencia. Adicionalmente, lo entiende como factor de bienestar y desarrollo y está consciente de que todos los colombianos tienen el compromiso y la responsabilidad de velar por su gestión, protección y salvaguardia (Ministerio de Cultura, n. d.).

${ }^{2}$ Los bienes materiales declarados como monumentos, áreas de conservación histórica, arqueológica o arquitectónica, conjuntos históricos, u otras denominaciones que, con anterioridad a la promulgación de esta ley, hayan sido objeto de tal declaratoria por las autoridades competentes, o hayan sido incorporados a los planes de ordenamiento territorial (Ministerio de Cultura, n. d.). 
imprescriptibles. La ley establecerá los mecanismos para readquirirlos cuando se encuentren en manos de particulares y reglamentará los derechos especiales que pudieran tener los grupos étnicos asentados en territorios de riqueza.

Conforme con lo anterior, se entiende como bienes de interés cultural aquellos bienes inmuebles que poseen valores históricos, arquitectónicos y culturales, los cuales deben ser protegidos por representar unas características representativas de una época, para que sirvan de identidad a las generaciones futuras.

Ahora bien, la Ley 397 de 1997 (Por medio de la cual se desarrollan los artículos 70, 71 y 72 y demás artículos concordantes de la Constitución Política y se dictan normas sobre patrimonio cultural, fomentos y estímulos a la cultura, se crea el Ministerio de la Cultura y se trasladan algunas dependencias), estableció que se consideraran como bienes de interés cultural aquellos bienes declarados monumentos nacionales con anterioridad a dicha ley.

A su vez, el literal b del artículo 4 de la Ley 397 de 1997, modificado por el artículo 1 de la Ley 1185 de 2008, establece que:

Se consideran como bienes de interés cultural, los del ámbito nacional, departamental, distrital, municipal, los territorios indígenas o de las comunidades negras de que trata la Ley 70 de 1993 y, en consecuencia, quedan sujetos al respectivo régimen de tales, los bienes materiales declarados como monumentos, áreas de conservación histórica, arqueológica o arquitectónica, conjuntos históricos, u otras denominaciones que, con anterioridad a la promulgación de esta ley, hayan sido objeto de tal declaratoria por las autoridades competentes, o hayan sido incorporados a los planes de ordenamiento territorial ${ }^{3}$.

Así pues, para poder proteger el patrimonio cultural de la nación y los bienes de interés cultural del ámbito nacional, el legislador a través de la Ley 397 de 1997, modificada por la Ley 1185 de 2008, empezó a regular las problemáticas que se presentaban en ese diario vivir, para lo cual decretó que dichos bienes serían inembargables, imprescriptibles e inalienables ya que son propiedad de entidades públicas, y estableció un régimen de protección el cual consagra que ningún bien que haya sido declarado bien de interés cultural del ámbito nacional o que esté dentro

\footnotetext{
${ }^{3}$ Ministerio de Cultura (n. d.).
} 
de su zona de influencia o área afectada podrá ser intervenido sin la autorización de la autoridad que lo haya declarado como tal.

Entendiéndose como intervención, según el numeral $2^{\circ}$ del artículo 11 de la Ley 397 de 1997, modificado por el artículo $7^{4}$ de la Ley 1185 de 2008 y posteriormente por el artículo 212 del Decreto-Ley 019 de 2012, lo siguiente:

\section{ARTÍCULO 212. RÉGIMEN ESPECIAL DE LOS BIENES DE INTERÉS} CULTURAL. El numeral 2 del artículo 11 de la Ley 397 de 1997, modificado por el artículo 7 de la Ley 1185 de 2008, quedará así:

2. Intervención. Por intervención se entiende todo acto que cause cambios al bien de interés cultural o que afecte el estado del mismo. Comprende, a título enunciativo, actos de conservación, restauración, recuperación, remoción, demolición, desmembramiento, desplazamiento o subdivisión, y deberá realizarse de conformidad con el Plan Especial de Manejo y Protección si este fuese requerido.

La intervención de un bien de interés cultural del ámbito nacional deberá contar con la autorización del Ministerio de Cultura o el Archivo General de la Nación, según el caso. Para el patrimonio arqueológico, esta autorización compete al Instituto Colombiano de Antropología e Historia de conformidad con el Plan de Manejo Arqueológico.

Asimismo, la intervención de un bien de interés cultural del ámbito territorial deberá contar con la autorización de la entidad territorial que haya efectuado dicha declaratoria.

La intervención solo podrá realizarse bajo la dirección de profesionales idóneos en la materia. La autorización de intervención que debe expedir la autoridad competente no podrá sustituirse, en el caso de bienes inmuebles, por ninguna otra clase de autorización o licencia que corresponda expedir a otras autoridades públicas en materia urbanística.

${ }^{4}$ La modificación de la disposición en cita, mediante el artículo 212 del Decreto-Ley 019 de 2012, hace alusión a la supervisión de profesionales en la materia debidamente registrados o acreditados ante la respectiva autoridad y no incide en el concepto de intervención, que fue conservado en los términos del artículo 7 de la Ley 1185 de 2008. No obstante, de encontrase que para la fecha en que sucedieron los hechos no se encontraba vigente el Decreto-Ley 019 de 2012, entiéndase el concepto de intervención en los términos del artículo 7 de la Ley 1185 de 2008 sin la posterior modificación. 
Quien pretenda realizar una obra en inmuebles ubicados en el área de influencia o que sean colindantes con un bien inmueble declarado de interés cultural, deberá comunicarlo previamente a la autoridad que hubiera efectuado la respectiva declaratoria. De acuerdo con la naturaleza de las obras y el impacto que pueda tener en el bien inmueble de interés cultural, la autoridad correspondiente aprobará su realización o, si es el caso, podrá solicitar que las mismas se ajusten al Plan Especial de Manejo y Protección que hubiera sido aprobado para dicho inmueble.

El otorgamiento de cualquier clase de licencia por autoridad ambiental, territorial, por las curadurías o por cualquiera otra entidad que implique la realización de acciones materiales sobre inmuebles declarados como de interés cultural, deberá garantizar el cumplimiento del Plan Especial de Manejo y Protección si este hubiere sido aprobado (Ley 1185, 2008, art. 7).

De tal manera, se entiende como área afectada la demarcación física del inmueble, conjunto de inmuebles, unidad predial, o según conste en el acto de declaratoria; y como zona de influencia lo comprendido por 100 metros lineales contados a partir de la finalización del área afectada por cada uno de sus fachadas hasta formar un polígono, y toma predios completos en los casos en que estos se vean afectados parcialmente. En caso de intersecar cursos de agua, se incluye la ribera opuesta ${ }^{5}$.

Ahora bien, cuando se realice alguna de las intervenciones expuestas en los párrafos anteriores, la Ley 1185 de 2008 en su artículo 10, faculta al Ministerio de Cultura para imponer sanciones, adelantar procedimientos administrativos sancionatorios y regula las faltas contra el patrimonio cultural de la nación.

ARTÍCULO 10. El artículo 15 de la Ley 397 de 1997 quedará así:

Artículo 15. De las faltas contra el patrimonio cultural de la nación. Las personas que vulneren el deber constitucional de proteger el patrimonio cultural de la nación, incurrirán en las siguientes faltas:

$(\ldots)$

Las que constituyen faltas administrativas y/o disciplinarias:

$(\ldots)$

${ }^{5}$ Ministerio de Cultura (n. d.). 
4. Si la falta consiste en la intervención de un bien de interés cultural sin la respectiva autorización en la forma prevista en el numeral 2 del artículo 11 de este título, se impondrá multa de doscientos (200) a quinientos (500) salarios mínimos legales mensuales vigentes por parte de la autoridad que hubiera efectuado la respectiva declaratoria. En la misma sanción incurrirá quien realice obras en inmuebles ubicados en el área de influencia o colindantes con un inmueble de interés cultural sin la obtención de la correspondiente autorización, de conformidad con lo previsto en el numeral 2 del artículo 11 de este título.

También será sujeto de esta multa el arquitecto o restaurador que adelante la intervención sin la respectiva autorización, aumentada en un ciento por ciento (100\%).

La autoridad administrativa que hubiera efectuado la declaratoria de un bien como de interés cultural podrá ordenar la suspensión inmediata de la intervención que se adelante sin la respectiva autorización, para lo cual las autoridades de policía quedan obligadas a prestar su concurso inmediato a efectos de hacer efectiva la medida que así se ordene. En este caso, se decidirá en el curso de la actuación sobre la imposición de la sanción, sobre la obligación del implicado de volver el bien a su estado anterior, y/o sobre el eventual levantamiento de la suspensión ordenada si se cumplen las previsiones de esta ley.

Lo previsto en este numeral se aplicará sin perjuicio de la competencia de las autoridades territoriales para imponer sanciones y tomar acciones en casos de acciones que se realicen sin licencia sobre bienes inmuebles de interés cultural en virtud de lo señalado en el numeral 2 del mismo.

$(\ldots)$

PARÁGRAFO $1^{\circ}$. El Ministerio de Cultura, (...) en lo de su competencia, quedan investidos de funciones policivas para la imposición y ejecución de medidas, multas, decomisos definitivos y demás sanciones establecidas por la ley, que sean aplicables según el caso.

PARÁGRAFO $2^{\circ}$. Para decidir sobre la imposición de las sanciones administrativas y/o disciplinarias y de las medidas administrativas previstas en este artículo, deberá adelantarse la actuación administrativa acorde con la Parte Primera y demás pertinentes del Código Contencioso Administrativo.

Así mismo, el Consejo de Estado ha manifestado: 
Es claro que si un bien ha sido declarado como parte del patrimonio cultural de la nación, corresponderá, en una primera instancia, a las autoridades nacionales regular lo concerniente a su conservación, señalando, si es del caso, su destinación, como parte del plan especial de protección que este está obligado a diseñar, a efectos de cumplir en debida forma la obligación de protección y conservación que ha impuesto la Constitución. En donde el legislador, en uso de su libertad de configuración, puede determinar, si lo considera necesario, el uso que ha de dársele, pertenezca este a un particular o a una entidad pública, en razón del interés público o social que tal declaración lleva implícito (Consejo de Estado, 2012, Sentencia 1459).

\section{Fortalezas del régimen legal de protección a los bienes de interés cultural del ámbito nacional}

Según lo expuesto en los acápites precedentes de este artículo, se dejó claro que los bienes de interés cultural del ámbito nacional son aquellos bienes inmuebles que poseen valores históricos, arquitectónicos y culturales los cuales deben ser protegidos por tener unas características representativas de una época, para que sirvan de identidad a las generaciones futuras (Higuera Jiménez, 2018).

Conforme con lo anterior, el régimen legal implementado para la protección de dichos bienes encuentra sus fortalezas en:

\section{Implementación de un procedimiento administrativo sancionatorio por infracción al régimen legal}

La Ley 397 de 1997 estableció en Colombia un régimen legal para sancionar a aquellas personas que adelantan intervenciones en los bienes de interés cultural del ámbito nacional sin contar con autorización de las entidades competentes, de conformidad con el artículo 72 de la Constitución Política el cual establece el deber de protección con el que debe contar el Estado para la protección del patrimonio cultural de la nación.

De tal modo, una de las fortalezas que representa este régimen legal es la sanción a la que están sometidas todas aquellas personas naturales o jurídicas que transgredan dicho ordenamiento y atenten contra la preservación y conservación del patrimonio cultural de la nación. 
Conforme con lo anterior, los bienes de interés cultural cuentan con un procedimiento administrativo sancionatorio para su protección, de conformidad con el artículo 47 del Código de Procedimiento Administrativo y de lo Contencioso Administrativo el cual es adelantado por el Ministerio de Cultura (Ley 1437, 2011, art. 47).

Dicho proceso cuenta con una etapa de averiguación preliminar la cual no constituye un requisito de procedibilidad, ya que su finalidad es recaudar el material probatorio suficiente para determinar la pertinencia de dar inicio a una actuación formal tal como lo ha manifestado el Honorable Consejo de Estado en su jurisprudencia:

Según se puede leer en la norma, la averiguación preliminar no está sujeta a formalidad alguna, y que su única finalidad es la de permitirle al ente de control contar con la información necesaria para establecer si se debe o no abrir una investigación administrativa, de modo que si ya dispone de ella en virtud de cualquier otro medio legal, la decisión de iniciar dicha investigación bien puede ser tomada sin que forzosamente deba surtirse averiguación previa alguna, de suerte que esta no es una etapa obligatoria del procedimiento sancionatorio (...).

Por consiguiente, de ser cierto que la investigación administrativa que se dispuso iniciar contra la actora, Derilac S. A. y otras empresas, mediante la Resolución Núm. 1635 de 1999, y que fue acumulada a la que se adelantaba contra la Asociación de Procesadores Independientes de Leche, no estuvo precedida de una averiguación preliminar específica, significa que la Administración contaba con los elementos suficientes para haber procedido así, que bien pudo haber obtenido de otra averiguación preliminar o incluso de otra investigación administrativa, y que por lo tanto no era necesaria tal averiguación. En estas circunstancias no tiene asidero el cargo de violación del debido proceso por no haberse surtido la misma (Consejo de Estado, 2000, Sentencia C-0665).

Una vez agotada dicha averiguación preliminar en los casos que sea imperioso para verificar la presunta intervención y recaudar la información necesaria para esclarecer los hechos e individualizar a los presuntos responsables y así determinar la existencia o no de una falta contra el patrimonio cultural de la nación, se sigue con la apertura del procedimiento administrativo sancionatorio y formulación de pliego de cargos, dentro del cual se consideran como presuntos infractores al 
propietario, arrendatario, tenedor, poseedor, arquitecto o restaurador de la ejecución de dichas intervenciones, los cuales contaran con un término de 15 días para rendir sus descargos, respecto a los hechos que se les atribuyen.

Una vez surtida está etapa, dentro de los 30 días siguientes cuando es un infractor o 60 días cuando son varios, se procede a abrir período probatorio según la solicitud de pruebas allegadas en los descargos y las pruebas de oficio que solicite el Despacho; cumplido esto, se dan 10 días para que presenten sus alegatos o conclusión y en los próximos 30 días se emite la resolución que impone la sanción o el archivo del expediente.

De allí que se desprenden otras dos fortalezas de la implementación de estos procesos:

\section{De la celeridad de las actuaciones}

Según la Corte Suprema de Justicia el principio de celeridad es aquel mediante el cual:

[...] los funcionarios públicos el objetivo de otorgar agilidad al cumplimiento de sus tareas, funciones y obligaciones públicas, hasta que logren alcanzar sus deberes básicos con la mayor prontitud, y que de esta manera su gestión se preste oportunamente cubriendo las necesidades y solicitudes de los destinatarios y usuarios, esto es, de la comunidad en general. Igualmente ha señalado esta Corporación, que este principio tiene su fundamento en el artículo $2^{\circ}$ de la Constitución Política, en el cual se señala que las autoridades de la nación tienen la obligación de proteger la vida, honra, bienes, creencias y demás derechos y libertades de los ciudadanos, al igual que asegurar el cumplimiento de los deberes sociales del Estado y de los particulares, lo cual encuentra desarrollo en artículo 209 superior al declarar que la función administrativa está al servicio de los intereses generales entre los que se destaca el de la celeridad en el cumplimiento de las funciones y obligaciones de la administración pública (Corte Constitucional, 2013, Sentencia C-826).

Aunado a lo anterior, el régimen legal de protección a los bienes de interés cultural se agota en un término relativamente corto ya que muchos de los procesos no pasan por la etapa de averiguación preliminar, lográndose resolver la situación jurídica que se presente respecto a las intervenciones realizadas en el término de 
un año siempre y cuando se cuente con material probatorio suficiente para endilgar una falta o proceder al archivo de la actuación.

\section{Vinculación del profesional que estuvo a cargo de la obra}

Cuando se tienen indicios de quién fue el arquitecto encargado de la ejecución de la obra o el restaurador, es posible iniciar un procedimiento administrativo sancionatorio contra estos, debido a que el Decreto 1077 de 2015 por medio del cual se expide el reglamento sector vivienda, ciudad y territorio en su artículo 2.2.6.1.1.9, dispone:

ARTÍCULO 2.2.6.1.1.9. Autorización de actuaciones urbanísticas en bienes de interés cultural. Sin perjuicio de lo dispuesto en el numeral 4 del artículo 2.2.6.1.2.1.11 del presente decreto, cuando se haya adoptado el Plan Especial de Manejo y Protección de Bienes de Interés Cultural por la autoridad competente, las solicitudes de licencias urbanísticas sobre bienes de interés cultural y sobre los inmuebles localizados al interior de su zona de influencia, se resolverán con sujeción a las normas urbanísticas y de edificación que se adopten en el mismo. En caso de no haberse adoptado el Plan Especial de Manejo y Protección al momento de la solicitud, las licencias se podrán expedir con base en el anteproyecto de intervención del bien de interés cultural aprobado por parte de la autoridad que efectuó la respectiva declaratoria, en el cual se señalará el uso específico autorizado.

PARÁGRAFO. El anteproyecto autorizado por la entidad que hubiere efectuado la declaratoria de Bienes de Interés Cultural no podrá ser modificado en volumetría, altura, empates ni condiciones espaciales, sin previa autorización por parte de la misma entidad (Decreto 1077, 2015).

Conforme con lo anterior, por ser una norma de obligatorio conocimiento para los arquitectos se les sanciona por el desconocimiento de la ley representado en la omisión del ejercicio de sus funciones, es decir, por no solicitar la autorización al Ministerio de Cultura teniendo el conocimiento de que debe agotarse esta etapa.

Así pues, la Ley General de Cultura en el primer párrafo del artículo 10 establece: 
(..)

También será sujeto de esta multa el arquitecto o restaurador que adelante la intervención sin la respectiva autorización, aumentada en un ciento por ciento (100 \%) (Ley 1185, 2008, art. 10).

\section{Su carácter pecuniario}

Las sanciones endilgadas en los procesos administrativos sancionatorios por omisión de las formalidades legales establecidas en la Ley 397 de 1997, modificada por la Ley 1185 de 2008, solo pueden ejercerse a través de multas que oscilan entre 200 y 500 SMLMV para las cuales a la hora de imponerse se tienen en cuanta los factores de agravación del Código de Procedimiento Administrativo y de lo Contencioso Administrativo junto con la afectación que se haya producido al bien de interés cultural.

ARTÍCULO 10. El artículo 15 de la Ley 397 de 1997 quedará así:

Artículo 15. De las faltas contra el patrimonio cultural de la nación. Las personas que vulneren el deber constitucional de proteger el patrimonio cultural de la nación, incurrirán en las siguientes faltas:

$(\ldots)$

Las que constituyen faltas administrativas y/o disciplinarias:

(...)

4. Si la falta consiste en la intervención de un bien de interés cultural sin la respectiva autorización en la forma prevista en el numeral 2 del artículo 11 de este título, se impondrá multa de doscientos (200) a quinientos (500) salarios mínimos legales mensuales vigentes por parte de la autoridad que hubiera efectuado la respectiva declaratoria. En la misma sanción incurrirá quien realice obras en inmuebles ubicados en el área de influencia o colindantes con un inmueble de interés cultural sin la obtención de la correspondiente autorización, de conformidad con lo previsto en el numeral 2 del artículo 11 de este título (Ley 1185, 2008, art. 10). 


\section{Caducidad}

Se establece un término de caducidad ${ }^{6}$ a la administración de 3 años, los cuales son contados desde la fecha en que se emite el auto de suspensión de las obras por parte del Ministerio de Cultura y a falta de este, se contará desde el día en que terminaron las intervenciones.

\section{De las medidas cautelares}

Según el parágrafo $1^{\circ}$ del artículo 15 de la Ley 397 de 1997, modificado por el artículo 10 de la Ley 1185 de 2008, todas las intervenciones que se realicen a los bienes de interés cultural del ámbito nacional deben estar sujetas al régimen precautelar y sancionatorio dispuesto en la Ley de Cultura.

Estableciéndose como medidas cautelares ${ }^{7}$, la

- Suspensión de las obras.

- Restitución del inmueble.

- Medidas cautelares innominadas para la conservación y protección de los Bienes de Interés Cultural.

- Su carácter de inembargabilidad.

- Como también funciones policivas para la suspensión de las obras.

${ }^{6}$ La caducidad es la extinción del derecho a la acción por cualquier causa, como el transcurso del tiempo, de manera que si el actor deja transcurrir los plazos fijados por la ley en forma objetiva sin presentar la demanda, el mencionado derecho fenece inexorablemente sin que pueda alegarse excusa alguna para revivirlos. "Dichos plazos constituyen entonces, una garantía para la seguridad jurídica y el interés general. $Y$ es que la caducidad representa el límite dentro del cual el ciudadano debe reclamar del Estado determinado derecho; por ende, la actitud negligente de quien estuvo legitimado en la causa no puede ser objeto de protección, pues es un hecho cierto que quien, dentro de las oportunidades procesales fijadas por la ley ejerce sus derechos, no se verá expuesto a perderlos por la ocurrencia del fenómeno indicado" (Corte Constitucional, 1998, Sentencia C-574).

${ }^{7}$ Para la Corte, las medidas cautelares, son aquellos instrumentos con los cuales el ordenamiento protege, de manera provisional, y mientras dura el proceso, la integridad de un derecho que es controvertido en ese mismo proceso. De esa manera el ordenamiento protege preventivamente a quien acude a las autoridades judiciales a reclamar un derecho, con el fin de garantizar que la decisión adoptada sea materialmente ejecutada. Por ello, esta Corporación señaló, en casos anteriores, que estas medidas buscan asegurar el cumplimiento de la decisión que se adopte, porque los fallos serían ilusorios si la ley no estableciera mecanismos para asegurar sus resultados, impidiendo la destrucción o afectación del derecho controvertido (Corte Constitucional, 2004, Sentencia C-379). 
Así pues, la Ley General de Cultura establece medidas cautelares: preventivas, en el sentido de que impiden que se efectúe una afectación a los bienes de interés cultural; conservativas, manteniendo o salvaguardando los valores históricos ante la presencia de intervenciones que puedan ponerlos en riesgo; y anticipativas, tales como la suspensión de obras para evitar perjuicios irremediables.

En efecto, el Consejo de Estado respecto a la suspensión de las obras ha manifestado:

La suspensión, corresponde a la medida tradicional en el proceso administrativo, la cual consiste en privar de forma temporal los efectos de una decisión administrativa. Discrecionalidad que le permite decretar todas aquellas que considere necesarias. No obstante, su decisión debe estar sujeta al principio de proporcionalidad.

Por lo tanto, en el examen de procedibilidad de la medida solicitada, debe verificarse la ocurrencia de los elementos tradicionales que ameritan la imposición de la cautela, es decir, fumus boni iuris o apariencia de buen derecho, periculum in mora o perjuicio de la mora y la ponderación de intereses (Consejo de Estado, 2016, Auto 2016-00498).

\section{El non bis in idem ${ }^{8}$ respecto a las sanciones por infracción al derecho urbanístico}

\section{La Ley 1185 de 2008 ha manifestado que:}

La autorización de intervención que debe expedir la autoridad competente no podrá sustituirse, en el caso de los bienes inmuebles, por ninguna otra clase de autorización o licencia que corresponda expedir a otras autoridades en materia urbanística.

En efecto, la autoridad administrativa que hubiere efectuado la declaratoria de un bien de interés cultural podrá ordenar la suspensión inmediata de la intervención que se adelante sin la respectiva autorización, para lo cual las autoridades de policía

${ }^{8} \mathrm{El}$ debido proceso es un principio de acuerdo al cual toda persona tiene derecho a unas garantías procesales mínimas en el marco de las actuaciones judiciales y administrativas. De acuerdo con el artículo 29 constitucional y en relación con el asunto que nos ocupa, implica i) que nadie puede ser juzgado "sino conforme a leyes preexistentes al acto que se le imputa, ante juez o tribunal competente" y, ii) que nadie puede ser juzgado dos veces por el mismo hecho (Corte Constitucional, 2013, Sentencia T-866). 
quedan obligadas a prestar su concurso inmediato a efectos de hacer efectiva la medida que así lo ordene. En este caso se decidirá en el curso de la actuación sobre la imposición de la sanción, sobre la obligación del implicado de volver el bien a su estado anterior, o sobre el eventual levantamiento de la suspensión ordenada si se cumplen las previsiones de esta ley.

En virtud de tal situación, es procedente citar la Sentencia C-088 de 2012 emitida por la Honorable Corte Constitucional, la cual dispuso:

La prohibición de doble enjuiciamiento no excluye que un mismo comportamiento pueda dar lugar a diversas investigaciones y sanciones, siempre y cuando estas tengan distintos fundamentos normativos, diversas finalidades. Esta Corte ha precisado que el non bis in ídem veda es que exista una doble sanción, cuando hay identidad de sujetos, acciones, fundamentos normativos, finalidad y alcances de la sanción (Corte Constitucional, 2012, Sentencia C-088).

Así las cosas, los procesos por presunta infracción urbanística son regulados de conformidad a las Leyes 388 de 1997, 810 de 2003 y al Decreto 1469 de 2010 ; y el Ministerio de Cultura, por su parte, investiga las presuntas faltas contra el patrimonio cultural de la nación materializadas con la intervención sin autorización del Ministerio de Cultura en un bien de interés cultural del ámbito nacional, inmuebles colindantes, ubicados en el área afectada o la zona de influencia de conformidad con la Ley 397 de 1997, modificada y adicionada por la Ley 1185 de 2008.

Así mismo, como lo manifestó la Honorable Corte Constitucional en la Sentencia C-554 de 2001 (magistrada sustanciadora Clara Inés Vargas Hernández):

La prohibición del non bis in idem no acarrea la imposibilidad de que unos mismos hechos sean castigados por autoridades de distinto orden; tampoco que esos hechos sean apreciados desde perspectivas distintas. Pero sí conlleva que autoridades del mismo orden y mediante procedimientos diversos sancionen repetidamente la misma conducta, como quiera se produciría una inadmisible reiteración del ius puniendi del Estado, y de contera, un flagrante atentado contra la presunción de inocencia (Corte Constitucional, 2001, Sentencia C-554-2001).

9 Decreto 1469 de 2010: "Por el cual se reglamentan las disposiciones relativas a las licencias urbanísticas; al reconocimiento de edificaciones; a la función pública que desempeñan los curadores urbanos y se expiden otras disposiciones". 
Pues bien, se trata de dos regímenes legales distintos que el legislador ha previsto en normas disímiles, sobre los cuales existe el juzgamiento por diferentes entidades del orden nacional y aunque hay identidad de causa, su objeto y faltas son totalmente diferentes ya que cada uno de los ordenamientos vela por la protección de un determinado interés.

\section{Obstáculos del régimen legal de protección a los bienes de interés cultural del ámbito nacional}

De acuerdo al marco normativo establecido en el primer título de este artículo, se tiene que los principales obstáculos con los que cuenta el régimen sancionatorio que propende por la salvaguardia y protección de los bienes de interés cultural son:

\section{Falta de participación comunitaria para denunciar las intervenciones}

Es necesario recordar que el inicio del proceso administrativo sancionatorio se da a partir de las denuncias ciudadanas presentadas ante el Ministerio de Cultura, ya sea por el servicio de PQRS, correo electrónico, correo certificado, publicaciones en periódicos o cuando funcionarios del Ministerio, como producto de visitas administrativas que realizan en el territorio nacional para verificar el estado de obras autorizadas o proyectos, evidencian que se están realizando intervenciones sin contar con la autorización de la entidad competente.

Así pues, se evidencia que muchas veces el Ministerio no alcanza a salvaguardar adecuadamente el patrimonio cultural de la nación porque recibe denuncias tardías después de varios años de intervención o muchas veces por falta de participación de la comunidad para denunciar las irregularidades e intervenciones que observa, constituyéndose así la falta de pertenencia e identidad cultural y uno de los problemas fundamentales para el inicio de los procesos administrativos sancionatorios. 


\section{Ineficacia de la sanción administrativa ante la ejecución del hecho}

Uno de los ejes fundamentales de la sanción es la orden de restitución del bien ${ }^{10}$ ante las intervenciones adelantadas sin los estudios, diseños, proyectos y autorizaciones correspondientes por parte del Ministerio de Cultura.

De tal manera, en algunos casos la sanción pecuniaria y la orden de restitución ${ }^{11}$ en cuanto a las intervenciones realizadas se configuran inútiles en aquellas inmuebles en los cuales se han realizado obras de demolición del bien, ya que de nada sirve ordenar la restitución del inmueble si se han perdido ya sus valores estéticos, simbólicos, físicos, históricos, artísticos y culturales.

En el caso en que más se evidencia la ineficacia de la sanción administrativa es en las intervenciones que se realizan a las estaciones de los ferrocarriles, como por ejemplo en la estación del ferrocarril de Armenia, o la casa de monseñor Arce en Popayán, Cauca, en las cuales a pesar de imponerse sanciones del máximo del quantum de la pena pecuniaria que es de 500 salarios mínimos legales mensuales vigentes (Ministerio de Cultura, 2018, Resolución Sanción 1108), es insuficiente e ineficaz para el fin que persigue la Ley General de Cultura, el cual es la protección, salvaguardia y protección de los bienes de interés cultural.

Tanto es así, que si se ordenara reconstruir y volver el inmueble a su estado anterior en materiales y fachadas, podría adaptarse a lo que anteriormente estaba allí pero ya no tendría los mismos valores históricos y culturales, tal y como lo ha manifestado la Corte Constitucional:

Los bienes de interés cultural (BIC) son representativos de determinadas épocas del desarrollo de la ciudad y que es necesario conservarlos como parte de la memoria cultural de los habitantes, por lo que le ha manifestado a los accionados que la conservación integral no permite ni ampliación ni obra nueva en el

${ }^{10}$ Se entiende por restitución del inmueble: "El resarcimiento de daños consistirá en la reposición de las cosas a su estado anterior, excepto si fuera imposible, en cuyo caso la indemnización se fijará en dinero. También podrá el damnificado optar por la indemnización en dinero; si un sujeto rompe un vidrio su obligación consiste en colocar otro igual; si destruye una pared en construirla nuevamente; si la construyó ilegalmente en demolerla; etc. De allí que la obligación de indemnizar se traduce, generalmente, en una prestación de hacer" (Kemelmarjer, 2016, pp. 1-2).

11 El dueño de un edificio es responsable de los daños que ocasione su ruina, acaecida por haber omitido las reparaciones necesarias, o por haber faltado de otra manera al cuidado de un buen padre de familia (Ley 84, 1873, art. 2350). 
predio. Siendo permitido solamente actividades de mantenimiento, adecuación funcional, consolidación, reconstrucción parcial, subdivisión por copropiedad y reparación locativa con el fin de conservar y recuperar la estructura original y sus principales características (Corte Constitucional, 2013, Sentencia T-537).

\section{Otorgamiento de licencias urbanistas sin el cumplimiento de los requisitos legales}

De conformidad con la Ley 397 de 1997 por medio de la cual se creó el Ministerio de Cultura como organismo rector de la cultura a nivel nacional, se establece que para la preservación del patrimonio cultural los planes de desarrollo de las entidades territoriales deberán estar armonizados con el Plan Decenal de Cultura y con El Plan Nacional de Desarrollo.

Así las cosas, al momento de expedir licencias urbanísticas estas deben cumplir con el Plan Especial de Manejo y Protección de los bienes de interés cultural, situación que no siempre es acatada por dichas autoridades ya que en la mayoría de casos expiden licencias de construcción sin el lleno de los requisitos legales tomándose atribuciones que no les corresponden, tal es el caso del curador urbano n. 2 de Armenia quien en la licencia de construcción n. ${ }^{\circ}$ 37-1520018 expedida el 12 de agosto de 2015, manifestó:

Hace parte integral del presente acto administrativo, la Resolución 3277 del 17 de octubre de 2014 otorgada por el Ministerio de Cultura, por medio de la cual se aprueba el plan especial de manejo y protección de la estación del ferrocarril de Armenia Quindío, localizada en la carrera 19 con calle 26 barrio La Estación, declarada monumento nacional, hoy bien de interés cultural del ámbito nacional (26 folios), dando cumplimiento a lo establecido en el numeral $4^{\circ}$, del artículo 2.2.6.1.2.1.11 del Decreto Único Reglamentario n. ${ }^{\circ} 1077$ del 26 de mayo de 2015, que establece "anteproyecto aprobado por el Ministerio de Cultura si se trata de bienes de interés cultural de carácter nacional o por la entidad competente si se trata de bienes de interés cultural de carácter departamental, municipal o distrital (...)” ( Ministerio de Cultura, 2018, Resolución Sanción 1512). 
Aun cuando el curador urbano n. 2 sabía de la prohibición de autorizar licencias de construcción sin el anteproyecto previo aprobado por el Ministerio de Cultura, procedió a autorizar la licencia de construcción sin este requisito, generando consecuencias irreparables en el patrimonio cultural de la nación, como lo fue la demolición de la estación del ferrocarril de Armenia para la adecuación de parqueaderos y una biblioteca pública.

Sobre este tema, la Honorable Corte Constitucional ha manifestado:

Considera oportuno la Sala señalar que esta situación se presenta también en otras ciudades del país, en las cuales las autoridades distritales o municipales otorgan licencias de construcción muchas veces de manera irracional, haciendo caso omiso de las insuficiencias existentes en materia de infraestructura adecuada de servicios públicos esenciales. Por ello, estima la Sala pertinente hacer un llamado de atención en general a todas las autoridades distritales o municipales del país, para que se abstengan de expedir licencias o permisos de construcción sin antes haber constatado, de manera fehaciente, que en los sectores para los cuales se otorguen dichas licencias o permisos... (Corte Constitucional, 1993, Sentencia T-366).

\section{Falta de competencia para sancionar a todos los actores que participan en el intervención}

Como se mencionó en el título de las fortalezas, la Ley General de Cultura (Ley 397 de 1997, modificada por la Ley 1185 de 2010) en su artículo 15 establece que los profesionales que vulneren el deber constitucional de proteger el patrimonio cultural de la nación, incurrirán en las siguientes faltas:

(...)

También será sujeto de esta multa el arquitecto o restaurador que adelante la intervención sin la respectiva autorización, aumentada en un ciento por ciento (100\%). (Ley 1185, 2010, art. 15).

Conforme con lo expuesto, es una sanción veraz que permite sancionar a aquellas personas que cuentan con los conocimientos técnicos y profesionales para tramitar adecuadamente esta clase de proyectos, y que a pesar de conocer los Planes 
Especiales de Manejo y Protección ${ }^{12}$ y el Decreto Único Reglamentario del Sector Vivienda, omiten la solicitud de autorización ante el Ministerio de Cultura.

Sin embargo, si se estudia a profundidad la norma y se aplica a los casos prácticos se evidencia un vacío legal ya que las sanciones establecidas en los procedimientos administrativos sancionatorios que adelanta el Ministerio de Cultura recaen solo sobre aquellos arquitectos que han sido encargados de las obras en su etapa de ejecución y no sobre los arquitectos proyectistas, ingenieros civiles, etc., que también participaron en la elaboración de planos, aprobación de licencias y ejecución de las obras, siendo un vacío legal a la hora de sancionar y establecer las medidas procedentes para su no repetición.

\section{Propuestas para fortalecer el régimen de protección de los bienes de interés cultural del ámbito nacional}

De acuerdo a cada uno de los lineamientos planteados a lo largo de este artículo, algunas de las acciones de mejora que se pueden implementar son:

\section{Vinculación de arquitectos proyectistas e ingenieros que intervinieron en cada uno de los pasos de la intervención}

E1 Decreto 1077 de 2015, por el cual se reglamenta el decreto único reglamentario sector vivienda, normativa que deben conocer cada uno de los arquitectos e ingenieros civiles del país, establece en su contenido que para poder realizar intervenciones en inmuebles declarados como bienes de interés cultural, área afectada

${ }^{12}$ El patrimonio cultural se protege y su normatividad es de superior jerarquía. Los bienes de interés cultural del orden nacional son declarados por el Ministerio de Cultura, dentro de ellos están los centros históricos (antes monumentos nacionales) y requieren Planes Especiales de Manejo y Protección antes llamados Planes Especiales de Protección y son el instrumento de gestión del patrimonio cultural de la nación. La Ley 388 de 1997 establece que el Plan de Ordenamiento Territorial (POT) es el instrumento básico para desarrollar el ordenamiento del territorio municipal, y el municipio, en ejercicio de su autonomía, promoverá dicho ordenamiento. Son elaborados por los municipios y adoptados por el concejo municipal, mientras que los Planes Especiales de Manejo y Protección son formulados por los municipios y aprobados por el Ministerio de Cultura. Los Planes Especiales de Manejo y Protección (PEMP) pueden limitar usos y edificabilidad de los planes de ordenamiento territorial. Es por esta razón que nuestro estudio se concentrará en establecer si los PEMP vulneran o no el principio de la autonomía y la descentralización administrativa (Garzón y Cely, 2012). 
o zona de influencia, deberán contar con previa autorización de la entidad que realizó la declaratoria.

Así pues, la sanción debería vincular a los ingenieros, arquitectos proyectistas, ya que su función también es velar por la salvaguardia, protección y conservación del patrimonio cultural, siendo sujetos sancionables.

En muchos de los procesos sancionatorios adelantados por el Ministerio de Cultura se evidencia que los arquitectos proyectistas e ingenieros civiles omiten presentar proyectos y solicitar intervenciones ante el Ministerio de Cultura terminando así las obras sin tramitar los permisos correspondientes.

Conforme con lo anterior, la sanción debería ser aplicada para estos sujetos igualmente que al arquitecto encargado, por el incumplimiento de los planes especiales de manejo y protección, por el Decreto Único Reglamentario Sector Vivienda, ya que expresamente menciona la prohibición sin obtener ningún castigo.

\section{Colocar la afectación que recae sobre el predio como una anotación en el certificado de tradición y libertad ${ }^{13}$}

El artículo 2.3.1.3 del Decreto 1080 de 2015 ha establecido que dentro de las competencias del Ministerio de Cultura está la de:

Informar a la correspondiente Oficina de Registro de Instrumentos Públicos para que incorpore la anotación en el folio de matrícula inmobiliaria respecto de los BIC inmuebles que declare, o los declarados con anterioridad a la expedición de la Ley 1185de 2008 en el ámbito nacional, así como sobre la existencia del PEMP aplicable al inmueble, si dicho plan fuese requerido. Igualmente, informar sobre la revocatoria de declaratorias (Decreto 1080, 2015, arts. 2.3.1.3).

Aunado a lo anterior, en la práctica aquellos inmuebles que son declarados como bienes de interés cultural del ámbito nacional cuentan con dicha anotación, pero los bienes colindantes, ubicados en el área afectada o zona de influencia no cuentan

${ }^{13}$ Es definido como el documento idóneo para obtener información sobre un inmueble desde el instante de la apertura del folio de matrícula hasta el día en que es elaborado por la Oficina de Registro de Instrumentos Públicos del lugar donde se encuentre ubicado. A través de este se indagan todos los datos jurídicos del predio sometido a registro en lo que tiene que ver con afectaciones, gravámenes, poseedor actual y poseedores anteriores en caso de haberlos tenido (concepto Notaría 19 de Bogotá). 
con dicha anotación de la afectación al dominio en el certificado de tradición y libertad, tanto así que a la hora de comprar los inmuebles y realizarle adecuaciones, se desconoce la calidad que tienen, generando un problema para los compradores y para el Estado, ya que su calidad de BICN debe ser de público conocimiento para así poder velar por una protección adecuada del patrimonio cultural de la nación ${ }^{14}$.

Ahora bien, se aclara que el desconocimiento de la ley no es excusa, y que uno de los principales objetivos del certificado de tradición y libertad es la publicidad, que es suplida a través de la publicación en el Diario Oficial de las resoluciones por las que se declara un centro histórico o a través de las cuales se expide un plan especial de manejo y protección, estando estos instrumentos y normas al alcance de toda la ciudadanía y que son de público conocimiento y deben ser acatadas.

Así pues, es necesario citar el artículo 119 de la Ley 489 de 1998, el cual establece:

\section{$(\ldots)$}

c) Los Decretos con fuerza de Ley, los Decretos y Resoluciones ejecutivas expedidas por el Gobierno Nacional y los demás actos administrativos de carácter general, expedidos por todos los órganos, dependencias, entidades u organismos del orden nacional de las distintas Ramas del Poder Público y de los demás órganos de carácter nacional que integran la estructura del Estado.

PARÁGRAFO. Únicamente con la publicación que de los actos administrativos de carácter general se haga en el Diario Oficial, se cumple con el requisito de publicidad para efectos de su vigencia y oponibilidad.

De esta manera se tiene que los actos administrativos de carácter general cumplen con el requisito de eficacia una vez son publicados en el Diario Oficial. Sobre este tema, el Consejo de Estado ${ }^{15}$ ha sido específico en señalar que:

${ }^{14}$ La Corte considera que la limitación al deber de protección del patrimonio cultural de la nación, contenida en la expresión demandada, resulta constitucionalmente válida por los siguientes cuatro motivos: en primer lugar, con anterioridad se expresó que el concepto de patrimonio cultural de la nación que desarrolla el primer inciso del artículo 4o de la Ley 397 de 1997, es amplio y subjetivo, de ahí que resulta razonable que se limite la aplicación de esa ley para el otorgamiento de estímulos y la imposición de restricciones solo a los bienes que el Ministerio de la Cultura, previa reglamentación de los criterios a evaluar, declare como de interés cultural (Corte Constitucional, 2006, Sentencia C-742).

15 
La validez del acto administrativo se remonta al momento de la expedición de la voluntad administrativa, mientras que la potencialidad de producir efectos jurídicos está ligada al hecho de que se cumpla con el requisito de publicación, aspecto externo que se requiere para que sea eficaz, es decir oponible a los administrados; ello implica que aunque, el acto administrativo existe con toda plenitud desde el momento en que se expide, su eficacia se encuentra ligada al cumplimiento del principio de publicación (Consejo de Estado, 2000, expediente 5722).

\section{Sanciones complementarias de acuerdo al principio de proporcionalidad}

Las sanciones establecidas en la Ley General de Cultura prevén que solo se aplicarán sanciones de tipo económico, los cuales oscilan entre 200 y 500 salarios mínimos legales mensuales vigentes.

Sin embargo, muchos de los casos oscilan en obras de restauración, las cuales realizan con el objetivo de mejorar y preservar las características originales de los inmuebles utilizando los mismos materiales para no alterar así su fachada, estructura y autenticidad.

Asociado a lo anterior, la falta contemplada en la Ley 397 de 1997, modificada por la Ley 1185 de 2008, establece que se aplicará a sanción a toda aquella persona que intervenga un bien sin la autorización del Ministerio de Cultura, para lo cual considero que se debería aplicar más a fondo el principio de proporcionalidad y no de manera objetiva con el contexto de la norma.

$\mathrm{Al}$ respecto, la Corte Constitucional ha establecido:

En cuanto al principio de proporcionalidad en materia sancionatoria administrativa, este exige que tanto la falta descrita como la sanción correspondiente a la misma resulten adecuadas a los fines de la norma, esto es, a la realización de los principios que gobiernan la función pública. Respecto de la sanción administrativa, la proporcionalidad implica también que ella no resulte excesiva en rigidez frente a la gravedad de la conducta, ni tampoco carente de importancia frente a esa misma gravedad (Corte Constitucional, 2003, Sentencia C-125). 
De conformidad con el citado principio, se debería tener en cuenta el grado de afectación que se causó con la intervención y la alteración que se haya podido producir con las obras al bien de interés cultural, bien colindante, o que esté en su zona de influencia; estableciendo si se cumple con los parámetros de conservación y protección manejados por el Ministerio de Cultura y si no se afectaron las características formales, condiciones estructurales, estéticas, tipología arquitectónica, función o sus valores culturales inherentes, promoviendo así a la preservación y mantenimiento de los bienes de interés cultural en condiciones óptimas.

\section{Capacitaciones $^{16}$}

En la práctica de las actuaciones administrativas sancionatorias, se evidencia muchas veces el desconocimiento por parte de la administración y de los habitantes de aquellos municipios, de los bienes de interés cultural con declaratoria.

Conforme con lo anterior, considero que sería viable capacitar a todas aquellas personas por conducto de la administración municipal porque, aunque los planes especiales de manejo y protección de los bienes de interés cultural están incluidos en los planes de ordenamiento territorial, muchas veces el ciudadano del común no tiene claridad sobre qué intervenciones puede realizar en su inmueble y mucho menos tener sentido de pertenencia ${ }^{17}$.

A su vez, se podrían implementar pautas educativas como las que realiza el Parlamento Andino ${ }^{18}$ que dentro de sus políticas de manejo al patrimonio cultural, ha establecido estrategias educativas que permiten la apropiación o sentido de pertenencia del patrimonio cultural, la exploración, la sensibilización y la formación

16 "Construyendo Legado Cultural" es un modelo de gestión cultural sostenible aplicado al patrimonio cultural de Suesca, Cundinamarca, que involucra a la comunidad en la gestión de proyectos culturales relacionados con el patrimonio, a través de la aplicación de un instrumento de acción participativa que le permite a la comunidad, con la mediación del gestor cultural, ser autogestora junto con el sector público y privado, de sus procesos culturales fortaleciendo su identidad cultural y fomentando el desarrollo del municipio (Castillo, 2012).

${ }^{17}$ Corresponde a los municipios preservar y defender el patrimonio cultural de su localidad, de ahí que, en principio, corresponde a dicha entidad territorial utilizar sus recursos económicos, humanos y logísticos para la protección de los bienes que integran su patrimonio cultural (Corte Constitucional, 2006, Sentencia C-742).

${ }^{18}$ La consagración constitucional que admita la validez y carácter vinculante de las normas andinas de derecho secundario o derivado del ordenamiento jurídico andino, permitiría mayor fluidez en la eficacia de las mismas (Blanco, 2011a). 
de autoridades policiales y judiciales evitando el daño y el deterioro de los bienes de interés cultural ${ }^{19}$ (Parlamento Andino, 2016).

\section{Conclusiones}

A lo largo de este artículo se pudo concluir que el patrimonio cultural es de gran importancia para la conformación de un país, ya que este dota a la nación de eminentes valores históricos, estéticos y símbolos que se esperan sean salvaguardados y protegidos para que sirvan de identidad a las generaciones futuras.

El patrimonio cultural de la nación no solo comprende costumbres, hábitats y tradiciones, sino que también hacen parte de este los bienes materiales e inmateriales, muebles e inmuebles; que respecto de los bienes inmuebles estos se categorizan en bienes de interés cultural del ámbito nacional, departamental, distrital y municipal los cuales se encuentran cobijados por un régimen legal de protección el cual está regido por la Ley 397 de 1997, modificada por la Ley 1185 de 2008.

Dentro de los bienes de interés cultural se encuentran los centros históricos, monumentos nacionales y bienes inmuebles que estén dentro del área afectada o zona de influencia de los referidos $\mathrm{BICN}$; entendiéndose como área afectada la demarcación física del inmueble, conjunto de inmuebles, unidad predial o como conste en el acta de declaratoria, es decir, aquellos inmuebles que son contiguos o colindantes con un BICN; y como zona de influencia lo comprendido por 100 metros lineales contados a partir de la finalización del área afectada por cada una de sus fachadas hasta formar un polígono y tomar predios completos en los casos en que estos se vean afectados parcialmente.

En aras de cumplir con el fin de la Ley General de Cultura el cual es la protección, conservación, restauración y salvaguardia de los bienes de interés cultural, se evidenció que era necesario imponer unas sanciones a todas aquellas personas naturales y jurídicas que realizaran intervenciones en dichos inmuebles sin contar

${ }^{19}$ La aspiración de la integración andina es el compromiso de los Estados andinos de consolidar intereses o valores comunes. Desde la creación de la Comunidad Andina fue clara la importancia de involucrar a la sociedad, razón por la cual, desde 1969 en el Acuerdo de Cartagena se estableció que dentro de los objetivos principales del proceso andino de integración está la promoción y el desarrollo equilibrado y armónico de los países miembros en condiciones de equidad, mediante la integración y la cooperación económica y social; manteniendo como directriz el mejoramiento persistente en el nivel de vida de los habitantes de la región. Desde el año 2007 la Comunidad Andina impulsó una transformación en la concepción y proyección del proceso y decidió promover una "integración integral" que buscara un acercamiento más equilibrado entre los aspectos sociales, culturales y económicos (Blanco, 2011b). 
con la autorización del Ministerio de Cultura. Por lo que en vigencia de la Ley 397 de 1997, modificada por la Ley 1185 de 2008, y en conexidad con el Código de Procedimiento Administrativo y de lo Contencioso Administrativo se crearon los procesos administrativos sancionatorios por infracciones a los bienes de interés cultural del ámbito nacional, inmuebles que se encuentren ubicados en el área afectada o su zona de influencia.

Dentro de dicho régimen legal de protección de los bienes de interés cultural se evidenciaron grandes fortalezas, entre ellas la implementación del citado procedimiento administrativo sancionatorio, regulado por el artículo 47 y siguientes del CPACA, donde, luego de observar alguna intervención consistente en obras de construcción, reestructuración, reparación, demolición u obras nuevas sin los requisitos legales, se da apertura a una averiguación preliminar (la cual es subsidiaria), formulación de pliego de cargos, período probatorio, alegatos de conclusión y la resolución de sanción o archivo, siendo un proceso rápido y eficaz.

En el marco de protección de los BICN únicamente se establecen sanciones pecuniarias las cuales oscilan entre los 200 y los 500 SMLMV, según la intervención realizada y el grado de afectación al BICN. Se sancionan también a sus propietarios, arrendatarios, usufructuarios, tenedores, poseedores, arquitectos encargados de la obra o restauradores, siendo otra de sus grandes fortalezas porque se vincula dentro del proceso administrativo sancionatorio al profesional encargado de la ejecución de la obra por su omisión en cumplir los requisitos legales establecidos en el Decreto Único Reglamentario Sector Vivienda, en los planes especiales de manejo y protección PEMP y en la Ley General de Cultura.

Se logró aclararle a la ciudadanía que las licencias de construcción otorgadas por las Secretarías de Planeación y las Curadurías Urbanas son ajenas a las autorizaciones que debe expedir el Ministerio de Cultura, por lo que no es válido excusarse en aducir que se tienen licencias de construcción válidamente otorgadas por una autoridad competente y que por ello no pueden ser sancionados, ya que dada la condición que recae sobre el inmueble, que sea BICN o esté ubicado en el área afectada o su zona de influencia, este debe contar obligatoriamente con autorización de la entidad que realizó la declaratoria.

Máxime que en aquellos inmuebles en los que se hayan iniciado intervenciones sin licencias de construcción y le sea adelantado algún proceso urbanístico y a su vez sea sancionado mediante resolución emitida por el Ministerio de Cultura, no puede alegarse tampoco el non bis in idem ya que la Corte Constitucional ha 
establecido que una misma actuación puede dar lugar a un doble enjuiciamiento cuando la conducta realizada tenga diferentes fundamentos normativos y diversas finalidades.

Una vez analizado todo el régimen legal, se pudo concluir que al igual que goza de variedad de fortalezas, a su vez en la vida práctica se desprenden muchos obstáculos que contribuyen a que muchas veces se pierdan las características de los bienes de interés cultural o sus valores históricos siendo ineficaz la sanción impartida; así mismo, se evidenció falta de sentido de pertenencia por parte de la comunidad al omitir presentar su queja ante el Ministerio de Cultura para que este pueda iniciar los procedimientos administrativos sancionatorios respectivos. Igualmente, persiste falta de sentido de pertenencia y de razonabilidad en aquellos servidores públicos que otorgan licencias de construcción sin el anteproyecto aprobado por el Ministerio, siendo este un requisito de procedibilidad para otorgar las licencias.

Aunque se establece en el régimen legal sancionar al arquitecto o restaurador encargado de la obra, en la vida práctica se evidencia que la sanción se queda corta ya que también debería recaer sobre aquellos arquitectos proyectistas e ingenieros civiles quienes diseñan, realizan los planos y en la mayoría de los casos, tramitan todas las licencias, generando con este actuar un menoscabo para el patrimonio cultural.

El régimen legal que protege a los bienes de interés cultural es desconocido por la mayoría de abogados ya que en las cátedras universitarias jamás se abordan estos temas, como también es desconocido por la ciudadanía, porque muchos saben que el territorio donde viven es catalogado como centro histórico, hoy bien de interés cultural, pero desconocen qué intervenciones pueden realizarse en estos, ante quiénes presentar las solicitudes de intervención y, más aún, si sus predios se encuentran dentro del área afectada o en la zona de influencia del BICN ya que no son capacitados por las autoridades territoriales y no se evidencia la afectación en el certificado de tradición y libertad.

Así pues, este artículo es de gran importancia para ayudar a concientizar a las personas en el respeto a los lineamientos establecidos en los planes especiales de manejo y protección, solicitar los permisos correspondientes ante el Ministerio de Cultura y velar por la conservación de los bienes de interés cultural del ámbito nacional como parte de la memoria cultural de las generaciones presentes y futuras. 


\section{Referencias}

Blanco, C. (2011a). La importancia social y política del Parlamento Andino. Revista IUSTA, 6(1), Recuperado de http://revistas.usantotomas.edu.co/index.php/viei/article/ view/2941.

Blanco, C. (2011b). Integración andina en el marco constitucional de los países miembros de la Comunidad Andina (CAN). Revista IUSTA, 1(4), 107-115. Recuperado de http:// revistas.usantotomas.edu.co/index.php/iusta/article/viewFile/3109/2976

Consejo de Estado. (2000). Sentencia C-0665. Sala de lo Contencioso Administrativo.

Consejo de Estado (2000). Expediente 5722. 3 de agosto de 2000, Sección Tercera, C. P. O. Navarrete.

Consejo de Estado. (2017). Auto n. 2016-00498. M. P. P. A. Cepeda, 27 de noviembre de 2017.

Consejo de Estado. (2012). Sentencia 1459. Sala de lo Contencioso Administrativo, Sección Primera, C. P. María Elizabeth García González, 10 de mayo de 2012.

Constitución Política colombiana. (1991). Asamblea Nacional Constituyente, Bogotá D. C., Colombia, 6 de julio de 1991.

Corte Constitucional. (1993). Sentencia T-366 de septiembre 3 de 1993. M. P. V. Mesa.

Corte Constitucional. (1998). Sentencia C-574 de octubre 14 de 1998. M. P. A. Carbonell.

Corte Constitucional. (2000). Sentencia C 557 de mayo 16 de 2000. M. P. V. Mesa.

Corte Constitucional. (2003). Sentencia C-125 de febrero 18 de 2003. M. P. M. Cabra.

Corte Constitucional. (2004). Sentencia C-379 de abril 27 de 2004. M. P. A. Sierra.

Corte Constitucional. (2011). Sentencia C-554 de mayo 30 de 2011. M. P. C. Hernández.

Corte Constitucional. (2012). Sentencia T-088 de febrero 16 de 2012. M. P. N. Pinilla.

Corte Constitucional. (2013). Sentencia C-826 de mayo 16 de 2013. M. P. V. Mesa.

Corte Constitucional. (2013). Sentencia T-537 de agosto 15 de 2013. M. P. J. Palacio.

Corte Constitucional. (2013). Sentencia T-866 de noviembre 27 de 2013. M. P. A. Ríos.

Corte Constitucional. (2016). Sentencia C-742 de agosto 30 de 2016. M. P. M. Cabra.

Decreto 1469. (2010). Por el cual se reglamentan las disposiciones relativas a las licencias urbanísticas; al reconocimiento de edificaciones; a la función pública que desempeñan los curadores urbanos y se expiden otras disposiciones. Diario Oficial n. ${ }^{\circ} 47.698$ de la República de Colombia, Bogotá D. C., Colombia, 30 de abril de 2010.

Decreto 1077. (2015). Por medio del cual se expide el Decreto Único Reglamentario del Sector Vivienda, Ciudad y Territorio. Diario Oficial n.o 49.523 de la República de Colombia, Bogotá D. C., Colombia, 26 de mayo de 2015. 
Garzón, M. A., y Cely, F. Y. (2012). Los planes especiales de manejo y protección para centros históricos y su incidencia en los principios de descentralización y autonomia de los municipios y distritos. Recuperado de https://repository.javeriana.edu.co/bitstream/handle/10554/10029/ FrenchyCelyLinaYanube2012.pdf?sequence=1\&isAllowed=y

Herrera, B. (2018). Derechos de los animales: la legislación nacional interna como barrera legal para el reconocimiento de la subjetividad jurídica animal. Revista Via Inveniendi et Iudicandi, 13(1), 55-93. DOI: http://dx.doi. org/10.15332/s1909-0528.2018.0001.02. Recuperado de http://revistas.usantotomas.edu.co/index.php/viei/article/view/4266/4043

Higuera Jiménez, D. M. (2018). Juicio a la legitimidad del legislador en Colombia. Revista Verba Iuris, 13(40), 25-47.

Kemelmarjer, A. (2016). Sistemas de reparación del daño causado. Recuperado de file:///C:/ Users/ariveros/Downloads/757-2875-1-PB\%20(2).pdf

Ley 70. (1993). Por la cual se desarrolla el artículo transitorio 55 de la Constitución Política. Diario Oficial n. ${ }^{\circ} 41.013$ de la República de Colombia, Bogotá D. C., Colombia, 31 de agosto de 1993.

Ley 397. (1997). Ley General de Cultura. Diario Oficial n. 43.102 de la República de Colombia, Bogotá D. C., Colombia, 7 de agosto de 1997.

Ley 489. (1998). Por la cual se dictan normas sobre la organización y funcionamiento de las entidades del orden nacional, se expiden las disposiciones, principios y reglas generales para el ejercicio de las atribuciones previstas en los numerales 15 y 16 del artículo 189 de la Constitución Política y se dictan otras disposiciones. Diario Oficial n. ${ }^{\circ} 43.464$ de la República de Colombia, Bogotá D. C., Colombia, 30 de diciembre de 1998.

Ley 1185. (2008). Por la cual se modifica y adiciona la Ley 397 de 1997 Ley General de Cultura y se dictan otras disposiciones. Diario Oficial n. ${ }^{\circ} 46.929$ de la República de Colombia, Bogotá D. C., Colombia, 12 de marzo de 2008.

Ley 1437. (2011). Por la cual se expide el Código de Procedimiento Administrativo y de lo Contencioso Administrativo. Diario Oficial n. ${ }^{\circ} 47.956$ de la República de Colombia, Bogotá D. C., Colombia, 18 de enero de 2011.

Llano, J. (2017). Teoría del derecho, neoconstitucionalismo y derechos diferenciados. Revista Verba Iuris, 12(38), 13-32.

Ministerio de Cultura. (s. f.). Patrimonio cultural en Colombia. Recuperado de http://www. mincultura.gov.co/areas/patrimonio/patrimonio-cultural-en-Colombia/Paginas/default. aspx

Ministerio de Cultura. (s. f.). Bienes de interés cultural del ámbito nacional. Recuperado de http://www.mincultura.gov.co/areas/patrimonio/patrimonio-cultural-en-Colombia/ bienes-de-interes-cultural-BICNAL/Paginas/default.aspx 
Ministerio de Cultura. (s. f.). Patrimonio cultural en Colombia. Recuperado de http://www. mincultura.gov.co/areas/patrimonio/patrimonio-cultural-en-Colombia/Paginas/default. aspx

Ministerio de Cultura. (s. f.). Trámites y servicios. Recuperado de http://www.mincultura. gov.co/areas/patrimonio/patrimonio-cultural-inmueble/patrimonio-arquitectonico/ Paginas/Tr\%C3\%A1mites-y-servicios.aspxLey 84. (1873). Por la cual se expide el Código Civil. Diario Oficial n. 2.867 de los Estados Unidos de Colombia, Bogotá, 26 de mayo de 1873.

Ministerio de Cultura. (2018). Resolución Sanción 1112 de 2018.

Ministerio de Cultura. (2018). Resolución Sanción 1108 de 2018.

Ministerio de Cultura. (2009). Resolución 2432 de 2009.

Notaría 19 de Bogotá. (s. f.). Importancia del Certificado de Tradición y Libertad. Recuperado de https://www.notaria19bogota.com/importante-certificado-libertad-tradicion/

Parlamento Andino. (2016). Marco normativo para la protección y salvaguardia del patrimonio cultural. Perú, enero de 2016. Recuperado de https://parlamentoandino.org/wpcontent/uploads/2018/01/4.-Marco-Normativo-Salvaguardia-y-Proteccio\%CC\%81ndel-Patrimonio.pdf 